\title{
O LÚDICO NA FORMAÇÃO DE PROFESSORES DE EDUCAÇÃO INFANTIL: TECENDO DIÁLOGOS, APRENDENDO COM AS CANTIGAS DE RODA
}

\author{
Maria Audenôra das Neves Silva Martins ${ }^{1}$ \\ Tereza Cristina Diniz de Abreu ${ }^{2}$
}

\section{RESUMO}

A importância da inclusão do lúdico e suas potencialidades para a construção da aprendizagem no contexto da Educação Infantil sempre desperta olhares e instiga diálogos e reflexões intensas entre educadores e suas práticas. Com vistas a tecer e ampliar o debate, o presente artigo é uma revisão bibliográfica e tem como objetivos pontuar a importância do lúdico na formação de professores; destacar a relevância do brincar para a criança na formação de professores de Educação Infantil e realçar a ludicidade das cantigas de roda como um instrumento capaz de construir saberes no processo do ensino e da aprendizagem. A metodologia realizada foi uma pesquisa bibliográfica, qualitativa e abordagem históricocultural, através de textos, artigos, dissertações, livros e documentos. Os aportes teóricos, como os de Brougère (1998), Charlot (2013), Huizinga (1990), Kishimoto (1997; 2005), Luckesi (2020), Martins (1993, 2003, 2012), Santos (2007), Vygotsky (1991, 2000), dentre outros teóricos, vêm fundamentar as nossas argumentações de que o professor precisa complementar sua formação técnica e pedagógica, com a formação lúdica como elemento estruturante do processo de ensinar e desencadeadores de aprendizagens significativas. A ludicidade se faz necessário porque a Educação Infantil precisa ser um espaço prazeroso, a infância é por excelência

\footnotetext{
${ }^{1}$ Doutora em Educação pela Universidade Federal do Rio Grande do Norte. Professora, pesquisadora e colaboradora do Programa de Pós-Graduação em ensino da UERN PPGE. ORCID: https://orcid.org/0000-0002-1110-8215 E-mail: audenoraneves@uern.br

${ }^{2}$ Mestre pelo programa de Pós-Graduação em Ensino, pela Universidade Estadual do Rio Grande do Norte, Campus de Pau dos Ferros (UERN). ORCID https://orcid.org/0000 0003-0733-7004 E-mail: cristinadinizcz@gmail.com
} 
o momento da brincadeira e as cantigas de roda proporcionam alegria, prazer para as crianças e para os professores e que necessitam ter o seu espaço reservado e preservado na infância e na escola.

Palavras-chave: Lúdico, Formação de professores, Educação Infantil, Cantigas de roda.

\section{THE LUDICIAN IN THE TRAINING OF CHILDREN'S EDUCATION TEACHERS: WEAVING DIALOGUES, LEARNING FROM THE WHEEL SINGER}

\section{ABSTRACT}

The importance of including playfulness and its potential for the construction of learning in the context of Early Childhood Education, always arouses glances and instigates intense dialogues and reflections, between educators and their practices. In order to weave and expand the debate, this article is a bibliographic review and aims to highlight the importance of playfulness in teacher education; to highlight the relevance of playing for the child in the formation of Early Childhood Education teachers and to highlight the playfulness of the cantigas de roda as an instrument capable of building knowledge in the teaching and learning process. The methodology used was a bibliographic, qualitative and historical-cultural approach, through texts, articles, dissertations, books and documents. Theoretical contributions, such as those by Brougère (1998), Charlot (2013), Huizinga (1990), Kishimoto (1997; 2005), Luckesi (2020), Martins (1993, 2003, 2012), Santos (1997), Vygotsky (1991, 2000), among other theorists, supports our arguments that the teacher needs to complement his technical and pedagogical training, with playful training as a structuring element of the teaching process and triggers of significant learning. Playfulness is necessary because Early Childhood Education needs to be a pleasurable space, childhood is the moment of play par excellence and the singing songs provide joy, pleasure for children and teachers and they need to have their space reserved and preserved in childhood and at school. 
Keywords: Playful, Teacher Training, Early Childhood Education, Cantigas de roda.

\section{EL LUDICIAN EN LA FORMACIÓN DE PROFESORES DE EDUCACIÓN INFANTIL: DIÁLOGOS DE TECHO, APRENDIENDO DE LAS CANTIGAS DE RODA}

\section{RESUMEN}

La importancia de incluir el juego y su potencial para la construcción del aprendizaje en el contexto de la Educación de la Primera Infancia, siempre despierta miradas e instiga intensos diálogos y reflexiones, entre los educadores y sus prácticas. Con el fin de tejer y expandir el debate, este artículo es una revisión bibliográfica y tiene como objetivo resaltar la importancia del juego en la formación docente; resaltar la relevancia de jugar para los niños en la formación de maestros de Educación Infantil y resaltar la alegría de las cantigas de roda como un instrumento capaz de construir conocimiento en el proceso de enseñanza y aprendizaje. La metodología utilizada fue un enfoque bibliográfico, cualitativo e histórico-cultural, a través de textos, artículos, disertaciones, libros y documentos. Contribuciones teóricas, como las de Brougère (1998), Charlot (2013), Huizinga (1990), Kishimoto (1997, 2005), Luckesi (2020), Martins (1993, 2003, 2012), Santos (1997), Vygotsky (1991, 2000), entre otros teóricos, respalda nuestros argumentos de que el maestro necesita complementar su formación técnica y pedagógica, con la formación lúdica como elemento estructurante del proceso de enseñanza y desencadenantes del aprendizaje significativo. La diversión es necesaria porque la Educación de la Primera Infancia debe ser un espacio placentero, la infancia es el momento de jugar por excelencia y las canciones para cantar brindan alegría, placer a los niños y a los maestros, y necesitan tener su espacio reservado y preservado en la infancia y en la escuela.

Palabras clave: Juguetón, Capacitación docente, Educación de la primera infancia, Cantigas de roda. 


\section{INTRODUÇÃO}

Ao longo dos anos, muitas reflexões e políticas públicas acerca da Educação Infantil foram construídas e remetem, antes de tudo, à busca de compreensões sobre os direitos que cingem essa que é considerada a primeira etapa da educação básica, dentre eles o direito de brincar. Nesse sentido, as reflexões para a construção deste artigo surgem, inicialmente, da conjectura de que o brincar, em toda a sua totalidade, é um instrumento de enfrentamento e intervenção essencial para a construção da aprendizagem.

À luz desse prisma, este artigo tem como objetivos pontuar a importância do lúdico na formação de professores; destacar o brincar e a sua importância para o desenvolvimento integral da criança; e como essa prática, na formação de professores de Educação Infantil, pode mediar a construção da aprendizagem na sala de aula. E, para contextualizar a dinâmica da ludicidade na vida do aluno e do professor, realçar a relevância das cantigas de roda como um instrumento capaz de construir saberes no processo do ensino e da aprendizagem.

Privilegiando as cantigas de roda, o texto revela a necessidade de a escola utilizar atividades que incluam textos literários, em que estejam presentes características do universo infantil, de modo a se respeitar a infância como fase de transformação, com elementos narrativos e poéticos importantes, os quais estimulam a sensibilidade e a degustação poética das crianças e podem, assim, beneficiar sua educação. Para Martins (2012, p. 19),

As cantigas de roda são poesias e poemas cantados em que a linguagem verbal (o texto), a música (o som), a coreografia (o movimento) e o jogo cênico (representação) se fundem numa única atividade lúdica.

As cantigas de roda, nas instituições escolares, não têm recebido dos profissionais da Educação Infantil a atenção que merecem, bem como o cancioneiro folclórico infantil, pois estes deveriam ter o seu lugar reservado na cultura lúdica. Faz-se necessário, na formação de professores, mostrar a importância da 
ludicidade através das cantigas de roda, para que se valorize o valor poético e estético, a natureza mito-poética da criança, fortalecendo, desse modo, o processo do ensino e da aprendizagem (MARTINS, 2003).

Nessa perspectiva, o presente texto está fundamentado em artigos que acostam as ideias de autores que fazem referências ao tema, sobre a concepção de criança e do brincar, destacando que tal ação é primordial para o desenvolvimento infantil e que, atrelada ao contexto educacional, em especial na formação de professores de Educação Infantil, torna-se indispensável para o processo de ensino e aprendizagem. Colaboram nessa construção textos que elevam a importância do lúdico na formação de professores, a exemplo das cantigas de roda como mais um instrumento relevante no processo, capaz de possibilitar a construção de saberes.

Para a construção do artigo, utilizou-se como procedimento metodológico uma abordagem qualitativa e estudo bibliográfico a partir de documentos, leis, livros, artigos científicos e dissertações que respaldaram as reflexões dialógicas e interpretações das autoras a respeito do tema apresentado. As análises realizadas diante da perspectiva exploratória, em consonância com as ideias dos autores pesquisados, contribuíram para a construção de um contexto sobre a temática, enfatizando a importância do lúdico nas formações de professores de Educação Infantil, destacando o brincar e a sua importância para o desenvolvimento integral da criança, bem como a relevância das cantigas de roda como um instrumento capaz de construir saberes no processo do ensino e da aprendizagem.

\section{EDUCAÇÃO INFANTIL: considerando alguns dados atuais}

A expansão da Educação Infantil no Brasil e no mundo tem ocorrido de forma crescente nas últimas décadas, acompanhando a intensificação da urbanização, a participação da mulher no mercado de trabalho e as mudanças na organização e estrutura das famílias. (BRASIL, 1998). A Educação Infantil é considerada a primeira etapa da educação básica e, respaldada na Filosofia, Psicologia, Sociologia, entre outras áreas do conhecimento, pode-se afirmar que esse nível de ensino, sendo o primeiro, é o mais importante para o 
desenvolvimento da criança, pois é nele que se constroem, estimulam-se ou criam-se as estruturas cognitivas.

Mas, diante de tantos avanços conquistados pela política educacional para a Educação Infantil nos últimos anos, os desafios para a construção de práticas docentes que fundamentem uma aprendizagem verdadeiramente significativa são muitos e estão longe de serem superados.

Nesse entendimento, alguns dados merecem ser considerados quanto ao atendimento da Educação Infantil no Brasil. O Instituto Nacional de Estudos e Pesquisas Educacionais Anísio Teixeira (Inep), em parceria com o Ministério da Educação (MEC), apresentou, em 2019, dados do Censo Escolar, com o crescimento acentuado das matrículas na Educação Infantil, com mais de 4,7\%. Segundo o Inep, o alto número se deu pela grande quantidade de matrículas, em 2015, em creches, com mais de 23\%. A maior concentração das matrículas de Educação Infantil de todo o país se concentra nas redes municipais de ensino, com o expressivo número de $71 \%$. O Inep traz ainda dados relevantes sobre a formação dos educadores, pois, com o aumento considerável de matrículas na Educação Infantil, em especial na rede pública, aumentou também a quantidade de professores com formação superior, no entanto, esse número ainda não atingiu nem $70 \%$ de professores com nível de graduação (BRASIL, 2020).

Com isso, observa-se o alarmante número de professores que não possuem ainda uma formação superior, e as inúmeras fragilidades quanto ao atendimento as crianças nos espaços educativos. É urgente consolidar políticas públicas com aceleradas mudanças em favor das melhorias em todos os aspectos do atendimento educacional para a infância, sobretudo para as formações de professores, pois somente através conhecimento crítico e reflexivo sobre a real importância lúdico é que os professores poderão incluí-lo em suas práticas pedagógicas.

Muitos são os meios para transformar uma sociedade, e a educação, sem dúvida, é o principal instrumento. Para Tfouni (2004), tanto a ausência quanto a presença da educação em uma sociedade são fatores importantes que atuam, ao mesmo tempo, como causa e consequência de transformações sociais, culturais e psicológicas. 
Dito isso, o atendimento à educação infantil precisa extrapolar de vez as marcas fracassadas do assistencialismo e priorizar a qualidade em todas as suas esferas. Como primeira etapa da educação básica, nos termos da Lei n 9.394/1996, o seu papel passa a ser não decisivo, mais essencialmente relevante para a transformação de uma sociedade democrática e reflexiva. No entanto, para que a Educação Infantil seja atendida dentro dos parâmetros que contemplem o desenvolvimento integral da criança, tendo o lúdico como instrumento fundamental para a construção da aprendizagem, as formações de professores precisam ser transformadas, repensadas, com vistas à qualidade e à inclusão do lúdico.

\section{O LÚDICO NA FORMAÇÃO DE PROFESSORES DE EDUCAÇÃO INFANTIL}

\section{A Ludicidade}

O lúdico na formação do professor deve se fazer presente em todos os cursos de licenciaturas. Mas, a ludicidade tem conquistado espaço na Educação Infantil por diversos motivos, por ser a brincadeira, o brinquedo e o jogo essenciais para a criança e a infância, permitindo aos professores um trabalho pedagógico prazeroso na construção de novos saberes (MARTINS, 2003; KISHIMOTO,1997; WAJSKOP, 1997; BROUGÈRE, 1998).

A ludicidade sempre se fez presente na história da humanidade, conforme preconiza Huizinga (1990, p. 7): "As grandes atividades arquetípicas da sociedade humana são, desde o início, inteiramente marcadas pelo jogo". O homem é um ser que realiza suas leis, ciências, poesias, guerras, filosofias e artes nutridas pelo extinto do jogo. Huizinga (1990) escreveu o clássico Homo Ludens, em que mostra o lúdico presente desde o início da civilização, por ser essencial ao homem.

Discorrer sobre a importância da ludicidade na formação do professor da Educação Infantil é transcender os limites da sua formação teórica e pedagógica. Negrine (1994) propõe a formação lúdica pautada nos argumentos de Santos $(2007$, p. 13) que destaca: 
Este tipo de formação é inexistente nos currículos oficiais dos cursos de formação do educador, entretanto algumas experiências têm mostrado sua validade e não são poucos os educadores que têm afirmado ser a ludicidade a alavanca da educação para o terceiro milênio.

Nesta perspectiva, por se tratar do lúdico na formação de professores, será assumido o conceito polissêmico da palavra, por se entender que a ludicidade é um fenômeno observado como ato social - ação como produto da cultura baseada nas ideias de Huizinga (1990), e por compreender que o professor, ao participar das atividades lúdicas na sua formação, vivencia suas subjetividades - a sensação de liberdade, um estado de plenitude e de entrega para essa vivência. Ancora-se nos fundamentos de Luckesi (2020), que pontua o estado interno da pessoa que vivencia a experiência lúdica, transcendendo as atividades objetivas descritas pela cultura. Ainda que os professores tenham a sensação de prazer no grupo, no coletivo, a ludicidade é interna, é subjetiva e esse detalhe fortalece os argumentos da necessidade da ludicidade na formação dos professores. Segundo Bock, Furtado e Teixeira (2002, p.23):

Subjetividade é a síntese singular e individual que cada um de nós vai constituindo conforme vamos nos desenvolvendo e vivenciando as experiências da vida social e cultural; é uma síntese que nos identifica, de um lado, por ser única, e nos iguala, de outro lado, na medida em que os elementos que a constituem são experienciados no campo comum da objetividade social.

Nessa linha de raciocínio, é visível a necessidade da formação lúdica para os professores da Educação Infantil. Segundo Santos (2007, p.13):

A formação lúdica se assenta em pressupostos que valorizam a criatividade, o cultivo da sensibilidade, a busca da afetividade, a nutrição da alma, proporcionando aos futuros educadores vivências lúdicas, experiências corporais, que se utilizam da 
ação, do pensamento e da linguagem, tendo no jogo sua fonte dinamizadora.

Neste sentido, quando mais o professor da Educação Infantil vivenciar a ludicidade na sua formação, maior será a sua chance de ser um professional capaz de trabalhar com a criança de forma prazerosa. Corrobora-se, neste estudo, que o professor é homemcorpo, homem-pensamento, homem-ação e tudo isso está sintetizado no termo subjetividade (BOCK; FURTADO; TEIXEIRA, 2002). Na verdade, a ludicidade traz de novo o fato de que 0 professor é um ser cujas emoções e sentimentos são construídos a partir das relações sociais. Por isso, na formação deve existir "[...] os três pilares: a formação teórica, a formação pedagógica e como inovação a formação lúdica" (SANTOS, 2007 p. 14), e o significado polissêmico da palavra ludicidade deve se fazer presente na formação do professor.

\section{Formação de professores com ludicidade}

A formação lúdica como complemento da formação teórica e pedagógica dos professores deve estar presente nas práticas pedagógicas das instituições educacionais, principalmente na Educação Infantil. Para isso, os cursos de formação de professores precisam incluir a brincadeira, o brinquedo e os jogos como instrumentos importantes do ensinar e do aprender, por serem prazerosos tanto para a criança como para os professores. O brincar, na formação lúdica, permite aos professores saberem suas possibilidades e suas limitações na utilização de atividades em sala de aula, além de desbloquearem resistências em relação ao seu uso, ampliando o olhar sobre a sua importância para a criança e para a Educação Infantil.

Atualmente, os professores ainda não atentaram para o poder da brincadeira na sala de aula como uma alternativa pedagógica natural, podendo, inclusive, através dela, buscarem novos conhecimentos, novos conceitos, desvendarem, ou melhor, darem a conhecer fatos e situações vivenciadas pela criança. Por outro lado, verifica-se que as brincadeiras atuais das crianças são muito 
"televisadas" e "contextualizadas", perdendo um pouco a espontaneidade, a criatividade e o tradicionalismo (MARTINS, 2003).

Sem dúvida, a formação lúdica de professores é uma das principais vias de acesso para que atividades lúdicas estejam presentes em todos os ambientes da Educação Infantil, ao passo que, para tanto, eles precisam de suporte teórico-metodológico eficaz para auxiliar suas ações. Assim, passam a ser agentes mediadores desse processo, conduzindo significativamente para que as brincadeiras, ao invés de serem consideradas como mero passatempo, sejam reconhecidas em toda a sua extensão e qualidade para o desenvolvimento infantil. Tal aspecto segue a compreensão de que, quando as atividades são mais dinâmicas e motivadoras, despertam 0 interesse da criança, contribuindo para o desenvolvimento intelectual e formação do pensamento lógico.

Nesse sentido, as contribuições de Saviani (2011, p. 65) são oportunas quando aponta que "O método é essencial ao processo pedagógico". Contudo, para a construção desse processo metodológico, ativo e mobilizador, o professor precisa, essencialmente, antes de tudo, se conscientizar de forma crítica e reflexiva da importância de suas ações para a transformação da realidade dos seus alunos. É na escola que o conhecimento organizado e socialmente construído, com bases críticas e reflexivas, possibilita o acesso democrático ao conhecimento (SAVIANI, 2011). Dessa forma, a ação docente deve ser constituída cotidianamente e, principalmente, baseada no conhecimento científico, na pesquisa e na práxis.

De acordo com as concepções de Rancière (2002), não se concebe a educação feita pelo distanciamento entre professor e aluno, ambos são conexos, definidos como "laço intelectual igualitário", pois ensinam e aprendem juntos; assim, a formação lúdica tem essa função porque permite ao adulto se conectar e compreender o mundo infantil, a vivenciar brincadeiras da criança, vivenciar e reviver, se possível, sua própria infância. Para Santos (2007 p. 14):

O adulto que volta a brincar não se torna criança novamente, apenas ele convive, revive e resgata com prazer a alegria do brincar, por isso é 
importante o resgate desta ludicidade, afim de que se possa transpor esta experiência para o campo da educação, isto é, a presença do jogo.

Esse resgate é necessário ao se analisar Saviani (2011), quando assegura que a pedagogia é a ação que pode tornar o homem plenamente humano e a ludicidade tem sido enfocada como uma alternativa, haja vista que, na formação lúdica, o professor é instigado a encontrar a sua própria identidade. Assim, a prática docente precisa ser pensada, é uma ação intencional, permeada por diversos saberes e experiências objetivas e subjetivas. Diante desse sujeito social e historicamente construído, o papel do educador carrega significados mais profundos, o de agente transformador, que quando consciente de suas ações, se torna capaz de trilhar novos caminhos para 0 conhecimento.

A construção do processo de ensino e aprendizagem compõe aspectos muito singulares, Charlot (2013) menciona que tal processo é inexistente quando o que se ensina não tem relação com o que se aprende, é preciso fazer a relação com o saber para que o aluno, ao se apropriar dele, passe a relacioná-lo com o mundo. Assim, o autor acredita que, ao mobilizar o professor e o aluno sobre o verdadeiro sentido do que se aprende em relação com o meio, desperta o interesse de aprender e de buscar novos conhecimentos. Para o autor, a mobilização no contexto educacional transcende a motivação. Segundo Charlot (2013, p. 180):

A estrutura antropológica do processo de ensinoaprendizagem decorre da condição humana. Por nascer inacabada, a criança deve aprender e, para tanto, mobilizar-se em uma atividade, em particular uma atividade intelectual. Por nascer em um mundo que a antecedeu, a criança deve ser ensinada. Não se pode aprender se não se é ensinado, de uma forma ou de outra; ninguém pode ser ensinado, seja qual for a pedagogia, se não se mobiliza a si mesmo em uma atividade. $\mathrm{O}$ ato de ensino-aprendizagem não é unicamente um encontro entre indivíduos, professor e aluno; é, mais profundamente, um processo antropológico que embasa a especificidade da espécie humana. 
No que tange às formações de professores de Educação Infantil, compreende-se que a ação docente é um dos verdadeiros impulsionadores de transformação social e educacional, porém, todo esse processo não se constitui de forma isolada. Inicialmente, é importante considerar que as formações de graduação das universidades também precisam estar alinhadas às demandas e problemáticas que afligem a educação básica em todos os seus aspectos e, assim, serem capazes de acobertar formações profissionais críticas e reflexivas e, principalmente, uma formação contínua, que possibilite renovar métodos, questionar e construir saberes.

À luz das informações, Santos (2007) faz considerações sobre o que é preciso para formar um educador e tece críticas quanto à descontextualização e ineficácia teórica dos cursos de graduação com as demandas sociais que se estabelecem nas escolas públicas, o que, consequentemente, contribui para uma formação de professores que, muitas vezes, os torna despreparados para atuarem juntos, em especial das turmas de Educação Infantil.

A esse respeito, a autora afirma que, somente a partir da compreensão dos sujeitos, do meio social, do papel da escola, da criança e suas especificidades é que o educador passa a constituir sua identidade profissional. No entanto, todo esse processo demanda tempo e mudanças de paradigmas em todas as esferas do conhecimento e formação docente e educacional. Uma verdadeira ruptura no pensamento e na reconstrução das formações de professores (SANTOS, 2007).

Diante das considerações, a formação de professores assume um caráter capaz de mobilizar e favorecer com que a ludicidade se torne instrumento de transformação na sala de aula. É cada vez mais crescente o conhecimento sobre a importância da inclusão do brincar na Educação Infantil, no entanto, percebe-se que muitas práticas docentes não contemplam essa ação. Martins (2003), em sua tese, contextualizou o problema da ruptura teoria e prática da ludicidade na Educação Infantil:

Em algumas pré-escolas, o espaço lúdico é muito privilegiado, a criança brinca demais, pois a concepção dos coordenadores, apoio técnico e 
professores é de que a Educação Infantil é apenas para brincar, despertar a imaginação, conforme depoimento de uma coordenadora de pré-escola pública. Esse brincar, todavia, não é uma atividade coordenada, observada por um profissional da Educação que tenha uma compreensão do lúdico no desenvolvimento infantil; é um brincar marcado por uma visão de criança, infância, Educação Infantil alienada da realidade e com total descompromisso com a educação pública (MARTINS, 2003, p. 18).

O cenário relatado pela pesquisadora aponta a necessidade do brincar de forma planejada, ficando evidente uma carência não só teórica, mas também de uma formação lúdica para os professores. Sendo assim, é pertinente refletir sobre os inúmeros problemas vivenciados na educação brasileira e seus conflitos diante de resultados tão assustadores em relação ao analfabetismo e seus altos índices. Em vista disso, é fundamental considerar e repensar todos os âmbitos para a construção de uma educação de qualidade social, de modo que é na Educação Infantil, primeira etapa da educação básica, que se pode começar o enfrentamento para a concretização de mudanças, através da formação lúdica do professor e, posteriormente, da inclusão do brincar na referida etapa.

\section{CONSTRUINDO SABERES COM AS CANTIGAS DE RODA}

Desde a mais tenra idade, a criança brinca para satisfazer uma necessidade de crescimento, de evolução da maturidade, seja pelo simples prazer, seja para ganhar uma competição. Em cada etapa da vida, a brincadeira tem uma função a cumprir no desenvolvimento da criança. Portanto, a brincadeira é indispensável à prática educativa, pois obedece às leis do desenvolvimento natural da criança. Perdendo ou participando da atividade sem a possibilidade de vitória, dada a natureza de determinados jogos e brincadeiras, o prazer e a satisfação coexistem da mesma maneira, porque o que a criança quer, acima de tudo, é viver a sua vida de participação, desempenhar o seu papel no mundo, criar uma realidade própria de acordo com suas habilidades, seus anseios e inclinações (MARTINS, 1993). 


\section{Brincando na Escola}

Diante de tantos avanços em favor da Educação Infantil, é importante que se destaque, de acordo com as definições na Lei de Diretrizes e Bases da Educação Nacional (Lei n 9.394/1996), a Base Nacional Comum Curricular - BNCC, documento que tem como finalidade orientar os currículos dos sistemas e redes de ensino de todo o país, bem como nortear as propostas pedagógicas, de escolas privadas ou públicas, da educação infantil ao ensino médio.

A Base Nacional Comum Curricular da Educação Infantil (BNCC-El) traz, em seu bojo, direitos de aprendizagens e desenvolvimentos à criança e uma estrutura curricular que objetiva guiar práticas pedagógicas que atendam mais especificamente a criança como sujeito de direitos. Apresenta seis direitos básicos de aprendizagens para todas as crianças: conviver, brincar, participar, explorar, expressar-se e conhecer-se.

A BNCC-EI (BRASIL, 2017, p.37) ressalta,ainda:

A interação durante o brincar caracteriza o cotidiano
da infância, trazendo consigo muitas aprendizagens
e potenciais para o desenvolvimento integral das
crianças. Ao observar as interações e a brincadeira
entre as crianças e delas com os adultos, é possível
identificar, por exemplo, a expressão dos afetos, a
mediação das frustrações, a resolução de conflitos e
a regulação das emoções.

Dessa forma, tais direitos fortalecem ainda mais a necessidade e a importância do brincar e das interações para contribuir no processo de desenvolvimento integral da criança. A construção de ações pedagógicas conscientes e planejadas, que possibilitem a aprendizagem das crianças e o desenvolvimento da sua capacidade de aprender, levam o professor, diariamente, a ressignificar a sua prática e mediar a relação da criança com o mundo, com as outras crianças e com o saber, através da convivência, da brincadeira, da participação, da exploração, se expressando e se conhecendo. A brincadeira é, para a criança, uma experiência criativa, uma forma básica de viver. Brincando, a criança adquire experiência e evolui, demonstrando habilidades inerentes ao seu desenvolvimento, as 
quais são alcançadas por meio de suas próprias brincadeiras ou daquelas elaboradas por outras crianças e pelos adultos (MARTINS, 1993).

Cháteau (1987, p. 14) menciona que "[...] uma criança que não sabe brincar, [...] será um adulto que não saberá pensar". Segundo Brasil (2002, p. 22): "[...] brincar é uma das atividades fundamentais para o desenvolvimento da identidade e da autonomia". O brincar é uma prática social viva, expressão cultural, pois pressupõe aprendizado social e culturalmente elaborados. A criança dá seu toque particular ao que faz, passo importante na construção da sua autonomia. É no brincar que a criança investiga e constrói conhecimentos sobre si e sobre o mundo.

Dentre todos os teóricos que desenvolveram estudos sobre atividades lúdicas, Piaget (1978) foi um dos que sistematizou todas as facetas da brincadeira no universo infantil. Não obstante todas as teorias mostrarem a importância da brincadeira para a criança, ela continua inaceitável por alguns educadores, principalmente na sala de aula. Eles duvidam da sua relevância no processo de ensino e aprendizagem. Para o adulto, a criança brinca porque não trabalha. $\mathrm{O}$ trabalho é o oposto da brincadeira. Percebe-se que, mesmo trabalhando, a criança também brinca, e brinca nos momentos mais difíceis da vida (MARTINS, 1993).

Logo, o brincar não é uma ação simbólica de mero passatempo, é uma ação que, intencionalmente fundamentada no contexto escolar, possibilita descobertas e aprendizagens significativas. Na brincadeira, a criança interage com o meio e explora, constrói e reconstrói conhecimentos, se insere em diversas realidades que lhe possibilitam construir conceitos, emoções e ideias a respeito do mundo de forma crítica. É através do lúdico que o professor, principal agente de mediação dessa prática, poderá favorecer que o universo infantil seja ricamente construído com bases sólidas de saberes significativos.

Enquanto alguns adultos entendem que a criança brinca porque não trabalha, tem direito à brincadeira porque é criança, restringindo o valor dessa atividade à característica apenas da infância, para os estudiosos, o valor da brincadeira é a história da personalidade da criança que se desenvolve no sentido de divertir, 
alegrar, formar e integrá-la no seu meio ambiente. Château (1987, p. 29) frisa que "Uma criança que não quer brincar/jogar é uma criança cuja personalidade não se afirma, que se contenta por ser pequena e fraca, um ser sem determinação, sem futuro".

Há ocasião em que a criança sente a necessidade da brincadeira na sala de aula. Impedida de brincar, ela sente o descaso da escola, que não a estimula, nem desenvolve suas habilidades para a aprendizagem. Constata-se que qualquer iniciativa da criança para brincar na sala de aula é bloqueada pela repressão da professora: "Fique quieto, faça suas tarefas, você está aqui para aprender, não para brincar". É muito comum observar crianças serem encaminhadas a programas de reeducação psicomotora, rotuladas de deficientes, desnutridas, desfavorecidas, indisciplinadas etc., quando, na verdade, o que lhes falta é a oportunidade de exercer atividades que explorem sua capacidade de movimento, sua criatividade e outras habilidades inerentes à sua condição, tão necessárias como subsídios para uma aprendizagem consistente (WAJSKOP, 1997).

Para os teóricos (pedagogos, psicólogos, sociólogos, etnólogos e educadores) que estudam a brincadeira de forma sistematizada, o valor da brincadeira é formativo, no sentido de desenvolver várias habilidades e atitudes na criança, como: cooperação, socialização, participação, reciprocidade, criatividade, percepção, comunicação, iniciativa, espontaneidade, relações interpessoais, autenticidade, aquisição de independência e tentativa de autoafirmação. Fica, assim, evidente a importância das atividades lúdicas na sala de aula e, para tanto, a necessidade do lúdico na formação dos professores.

\section{Cantigas de Roda}

Considerando as especificidades das crianças nesse encontro com as cantigas de roda, elas serão respeitadas nas suas diferenças individuais, sociais, econômicas, culturais, étnicas e religiosas. O brincar na sala de aula, direito garantido na legislação, será compreendido como forma particular de expressão, pensamento, interação e comunicação infantil por entender-se que "[...] o acesso das crianças aos bens socioculturais disponíveis, ampliando o 
desenvolvimento das capacidades relativas à expressão, à comunicação, à interação social, ao pensamento, à ética e à estética [...]" (BRASIL, 1998, p. 13) são experiências oferecidas à criança que podem contribuir para o exercício da cidadania.

É notório que toda ação educativa precisa ser intencional e a ação lúdica possui um imenso leque de possibilidades para o desenvolvimento físico, motor, cognitivo e social, pois envolve brincadeiras livres, brincadeiras cantadas, cantigas de roda, jogos. Dentro dessa diversidade lúdica, é fundamental destacar a música e as cantigas de roda por trazerem essencialmente, em seu eixo, um conjunto de saberes, magia e encantamento. As cantigas de roda no contexto da Educação Infantil, favorece a construção da aprendizagem, da expressão cultural, da leitura, da expressão comunicativa e interativa. Martins (2012) destaca as possibilidades poética e estética das cantigas de roda na Educação Infantil.

No entanto, as cantigas de roda, nas instituições escolares, principalmente na Educação Infantil, não têm recebido dos educadores a atenção que merecem, nem como cancioneiro folclórico infantil, pois deveriam ter o seu lugar reservado na cultura lúdica, muito menos como poesia. Como poesia, desconhecem a importância da versificação na educação pré-escolar, o valor poético e estético das cantigas de roda, a natureza mito-poética da criança, além do desconhecimento científico para se lidar com ensino da Arte na escola (MARTINS, 2003). Trata-se de uma ferramenta lúdica, capaz de compor o universo infantil, proporcionando o conhecimento de si e do mundo. O Referencial Curricular Nacional para a Educação Infantil (RCNEI) aponta que:

Ouvir música, aprender uma canção, brincar de roda, realizar brinquedos rítmicos, jogos de mãos, etc., são atividades que despertam, estimulam e desenvolvem o gosto pela atividade musical, além de atenderem a necessidades de expressão que passam pela esfera afetiva, estética e cognitiva. Aprender música significa integrar experiências que envolvem a vivência, a percepção e a reflexão, encaminhando-as para níveis cada vez mais elaborados. (BRASIL, 1998, p.48) 
Assim, através de uma ação docente efetivamente significativa, as cantigas de roda levam não apenas a desenvolver a musicalidade na Educação Infantil, mas também a assimilação de conhecimentos, a ação coletiva, interpretação textual, habilidades corporais, reflexão, criticidade, apropriação e desenvolvimento da fala.

As cantigas de roda assumem um papel desafiador para o professor em sala de aula, porém, não se limitam apenas a uma brincadeira livre e social, haja vista que vêm com uma carga de sentimentos, valores, regras, criticidade e linguagens. De acordo com Nicolau e Dias (2003, p.78):

As brincadeiras de roda assumem grande importância por levar a formação do círculo, situação em que o grupo pode-se comunicar frente a frente. Dando as mãos, as crianças formam um todo. Cantam, dançam ou tocam juntas; criam e seguem regras, exercitam textos e movimentos de forma coletiva, desenvolvendo a socialização e praticando democracia com valores de respeito mútuo, cooperação e unidade de grupo.

Considerando essas ideias, Martins (2012, p. 73) afirma:

Vivenciando as cantigas de roda, a criança incorpora as vocalizações rítmicas, revelando o papel comunicativo, expressivo e social que a linguagem desempenha no seu desenvolvimento e aí percebese a força da tradição oral.

A autora reforça a ideia de que as cantigas de roda trazem, em sua totalidade, um caminho de letramento a ser explorado. Ademais, a ação interpretativa que esses textos oferecem conduz a um processo de ensino e aprendizagem que vai além de uma simples brincadeira, uma verdadeira mobilização de interesses e apropriação de conhecimentos e saberes plurais.

Levar a criança a uma compreensão para além do que se apresenta no texto musicado, ou seja, interpretar as entrelinhas, é conduzir a criança a um complexo processo de desenvolvimento mental e histórico crítico, fundamental à construção educativa e a 
formação cidadã. Por conseguinte, as brincadeiras, as cantigas de roda na Educação Infantil se tornam, entre outros, instrumentos mediadores de enfrentamento e luta em favor da superação dos problemas educacionais e, principalmente, da construção educativa de cidadãos reflexivos e críticos.

\section{CONSIDERAÇÕES FINAIS}

Para concluir, é possível evidenciar a importância do lúdico na formação de professores de Educação Infantil, como um instrumento mediador e indispensável para a construção da aprendizagem, capaz de contribuir, ainda, para o enfrentamento e melhorias educacionais. Ao brincar, a criança aprende, desenvolve suas habilidades e suas potencialidades, constrói seus pensamentos, seus sentimentos e seus saberes, descobre seus limites, se constrói como ser único.

Quando brinca, a criança se desenvolve de forma integral, interage, conhece o mundo. No entanto, para que esse direito seja efetivamente garantido e que o brincar favoreça todas essas conquistas para a criança, é preciso também o conhecimento e a ação mediadora do professor, através do planejamento, da organização, e da mobilização para que a aprendizagem aconteça.

É na brincadeira que a criança constrói seus valores, sua identidade e sua autonomia. De forma breve, ressalta-se o quanto a Educação Infantil avançou, com políticas públicas de valorização e garantias de direitos, assegurando cada vez mais sua importância no cenário educacional. Mas, para tanto, é fundamental a implementação de políticas públicas de formação de professores de Educação Infantil, a partir de uma formação lúdica incorporada em seus currículos, tendo como um dos instrumentos principais da prática docente o brincar.

As práticas educativas devem possibilitar à criança produzir novos conhecimentos a partir dos que já tem e em interação com novos desafios. Mas as cantigas de roda não podem ser ensinadas como outros conteúdos; elas precisam ser vividas, sentidas, experimentadas, descobertas e, para isso, não basta apenas apresentar à criança brincadeiras, brinquedos e jogos. Fazem-se necessárias a paixão por parte do professor pesquisador, a 
sensibilidade e a instrumentação docente adequadas para que o trabalho atinja seus objetivos, ou seja, a sua formação lúdica. E aqui retoma-se o sentido polissêmico do lúdico na formação do professor: ele precisa ser sensível e ter o olhar sensível às cantigas de roda, à infância e à criança da Educação Infantil diante de uma realidade que reclama por alternativas pedagógicas capazes de melhorar o processo do ensinar e do aprender na sala de aula.

As formações de professores precisam ser repensadas, pois tem um papel primordial de favorecer procedimentos teóricos e metodológicos para que o professor organize ações lúdicas e criativas, como jogos, brincadeiras e cantigas de roda. Certamente, é possível compreender que a garantia de uma Educação Infantil de qualidade social, com vistas ao desenvolvimento integral da criança, passa fundamentalmente pelo brincar na Educação Infantil e pela formação dos professores.

Em vista disso, compreende-se ainda que a qualidade no ensino desde a Educação Infantil, primeira etapa da educação básica, contribui significativamente para que toda a educação construa caminhos sólidos do conhecimento e da aprendizagem, os quais irão favorecer amplamente a sua melhoria.

Compreender e praticar o lúdico, as possibilidades e os significados das brincadeiras, as cantigas de roda, o mundo do faz de conta, contribuem para o desenvolvimento cognitivo da criança, passa a ser não uma opção para a prática docente, mas, essencialmente, uma necessidade.

Privilegiando as cantigas de roda, este estudo revela a reflexão, na Educação Infantil, quanto à necessidade de a escola utilizar atividades com textos literários em que estejam presentes características estéticas e poéticas. As cantigas de roda têm conteúdo imaginativo no tratar de questões pertinentes ao universo da infância, são textos que respeitam a infância como fase de transformação; e foram selecionadas por se tratar de poesias em que estão presentes elementos narrativos e poéticos importantes, que estimulam a sensibilidade e a degustação poética das crianças e que podem, portanto, beneficiar sua educação.

Enfim, diante das considerações teóricas, dos diálogos e das reflexões tecidas neste artigo, conclui-se que é de fundamental 
importância manter sempre vivas as discussões acerca da importância do lúdico na Educação Infantil, como um dos instrumentos mais completos para o desenvolvimento integral da criança. No entanto, trata-se da formação de professores o principal espaço de construção do pensamento reflexivo, capaz de fomentar discussões para se estabelecer uma prática pedagógica consciente e crítica, tendo o lúdico como primazia para a construção da aprendizagem e desenvolvimento infantil.

\section{REFERÊNCIAS}

BOCK, A. M.; FURTADO, O.; TEIXEIRA, M. L.T. Psicologias. Uma introdução ao estudo de Psicologia. 13. ed. São Paulo: Saraiva, 2002.

BRASIL. Instituto Nacional de Estudos e Pesquisas Educacionais Anísio Teixeira (Inep). Censo da Educação Básica 2019: notas estatísticas. Brasília, 2020.

BRASIL. Base Nacional Comum Curricular (BNCC). Educação é a Base. Brasília, MEC/CONSED/UNDIME, 2017. Disponível em:

http://basenacionalcomum.mec.gov.br/images/BNCC_publicacao.pd f. Acesso em: 25 maio 2020.

BRASIL. Referencial Curricular Nacional para a Educação Infantil. Brasília: MEC/SEF, 1998. Disponível em:

http://portal.mec.gov.br/seb/arquivos/pdf/rcnei_vol1.pdf. Acesso em: 15 maio 2020.

BROUGÈRE, G. Jogo e Educação. Trad. Patrícia Chittoni Ramos. Porto Alegre: Artes Médicas, 1998.

CHARLOT, B. Da relação com o saber às práticas educativas. São Paulo: Cortez, 2013.

CHATEAU, J. O Jogo e a criança. São Paulo: Summus, 1987.

HUIZINGA, J. Homo Ludens. Tradução João Paulo Monteiro. São Paulo: Perspectiva, 1990.

KISHIMOTO, T. M. (Org.) Jogo, brinquedo, brincadeira e a educação. 8. ed. São Paulo: Cortez, 2005. 
KISHIMOTO, T. M. Jogo, brinquedo, brincadeira e a Educação. 2. ed. São Paulo: Cortez, 1997.

LUCKESI, C. Ludicidade e atividades lúdicas: uma abordagem a partir da experiência interna. Disponível em: www.luckesi.com.br. Acesso em: 27 maio 2020.

MARTINS, M. A. N. S. Brincadeira infantil: do imaginário ao real aspectos cognitivos e sociais. 1993. Dissertação (Mestrado em Educação) - Centro de Ciências Sociais Aplicadas, Universidade Federal do Rio Grande do Norte, Natal, 1993.

MARTINS, M. A. N. S. Cantigas de roda: o estético e o poético e sua importância para Educação Infantil. 2003. Tese (Doutorado) - Centro de Ciências Sociais Aplicadas, Universidade Federal do Rio Grande do Norte, Natal, 2003.

MARTINS, M. A. N. S. Cantigas de roda: o estético e o poético e sua importância para Educação Infantil. 1.ed. Curitiba, PR: CRV, 2012.

NEGRINE, A. Aprendizagem e Desenvolvimento Infantil:

Simbolismo e Jogo. Porto Alegre: PRODIL,1994.

NICOLAU, M. L. M.; DIAS, M. C. M. (Orgs.). Oficinas de sonho e realidade na formação do educador da infância. Campinas, SP: Papirus,2003.

PIAGET, J. A formação do símbolo na criança: imitação, jogo e sonho, imagem e representação. 3. ed. Rio de Janeiro: Guanabara, 1978.

RANCIÈRE, J. 0 mestre ignorante. Cinco lições sobre a emancipação intelectual. Tradução de Lilian do Valle. Belo Horizonte: Autêntica, 2002.

SANTOS, M. P. S. (Org.). O Lúdico na Formação do Educador. 7. ed. Petrópolis, RJ: Vozes, 2007.

SAVIANI, D. Pedagogia histórico-crítica: primeiras aproximações. 11. ed. Campinas, SP: Autores Associados, 2011.

TFOUNI, L. V. Letramento e Alfabetização. 6. ed. São Paulo: Cortez, 2004. 
VYGOTSKY, L. S. A formação social da mente. Trad. José Cipolla Neto et al. 5. ed. São Paulo: Martins Fontes, 1991.

VYGOTSKY, L. S. Pensamento e linguagem. Trad. Jefferson Luiz Camargo. São Paulo: Martins Fontes, 2000.

WAJSKOP, G. O brincar na pré-escola. 2. ed. São Paulo: Cortez, 1997.

Submetido em: Junho/ 2020.

Aceito em: Janeiro/ 2021. 